Meta

Journal des traducteurs

Translators' Journal

\title{
Translation is a Two-Way Street : A Response to Steiner
}

\section{Elizabeth Neild}

Volume 34, numéro 2, juin 1989

URI : https://id.erudit.org/iderudit/003698ar

DOI : https://doi.org/10.7202/003698ar

Aller au sommaire du numéro

Éditeur(s)

Les Presses de l'Université de Montréal

ISSN

0026-0452 (imprimé)

1492-1421 (numérique)

Découvrir la revue

Citer cet article

Neild, E. (1989). Translation is a Two-Way Street : A Response to Steiner. Meta, 34(2), 238-241. https://doi.org/10.7202/003698ar d'utilisation que vous pouvez consulter en ligne.

https://apropos.erudit.org/fr/usagers/politique-dutilisation/ 


\section{TRANSLATION IS A TWO-WAY STREET : A RESPONSE TO STEINER}

ELIZABETH NEILD

Harvard University, Cambridge, Massachusetts, USA

In some ways, Steiner's theory of translation is still the most far-reaching and comprehensive examination of the question we have, since he examines the problem in the broadest cultural context. There are, however, some important elements missing from his theory. In a theory based on a view of translation as interpretation, Steiner fails to discuss the seductiveness of the text - the text's movement towards or desire for its own interpretation - the way it reaches out to the reader. He also fails to give sufficient weight to the personal nature of the interpretive act itself. Finally, he fails to discuss the moment of encoding - the moment of writing - which for many theorists is the whole of translation. Clearly, this moment in the translation process is of major importance, since it entails the minor differences between languages which cannot finally be eliminated. These lacunae in Steiner's theory ${ }^{1}$ become very striking when one looks at the theory in the light of contemporary interpretation theory in literature (including feminist reading theory) and, of course, contemporary writing theories, especially those influenced by the work of Jacques Derrida.

It is common to see the translation and its original as somehow resembling the protagonist and his double found in the Doppelgänger motif so prevalent in late nineteenth century literature. Steiner himself uses the analogy as it has so often been used - to emphasize the interchange which takes place - the reciprocity which is an integral element of the relationship between the translation and its original. ${ }^{2}$ Indeed, such reciprocity is an important element in Steiner's theory, and one that he takes much further than most theorists. For certain moments in the interpretive act, however, I would take it even further than he does - I would claim that the reciprocity between the text and the interpreter-translator is even greater than that; the text reaches out to its interpreter as actively as the interpreter reaches out to the text.

Steiner posits a four-part hermeneutic motion, consisting of four stages. ${ }^{3}$ The first of these is trust: the interpreter / translator shows confidence that there is something there to be interpreted, and therefore makes a movement toward the text. The second stage is penetration (he enters into the text); the third is incorporation (he violently wrenches the original out of its context and makes it his own). Finally, Steiner sees as the fourth stage restitution - and it is here that his idea of reciprocity really comes into play. In this fourth and last stage the translator restores equilibrium between the source text and the translation by some form of exchange. I have retained Steiner's terminology here. What is most striking about his description is the violence of the language he uses, as well as its sexual nature.

The first of these steps, trust, is seen as a voluntary, active step on the part of the translator. In other words, it is the translator who chooses to move toward the text, believing that there is something there to be appropriated. But is the process really that simple? Is the text as passive an object as Steiner's description of the first step of the hermeneutic motion would have us believe? More than one theory of translation would claim that things are a great deal more complicated than this. Walter Benjamin, in "The Task of the

Meta, XXXIV, 2, 1989 
Translator," claims that the great work is testing the limits of language, and in a sense demands to be translated: "For to some degree all great texts contain their potential translation between the lines." 4 Benjamin's subject is literary translation, and his theory sees information as the least important thing to be translated. But I would claim that the reaching out on the part of the text is even stronger in the case of texts whose primary function is to convey information. Texts, particularly pragmatic texts, are not inert, self-reflexive objects, but are, on the contrary, reaching out to the world, and striving to act upon it.

Thus, the first part of Steiner's four-part hermeneutic motion needs rectification; he is correct when he claims that the translator shows confidence that there is something there to interpret, but he fails to explain one of the reasons for this confidence - the openness, or even the seductiveness, of the text to interpretation. If the interpreter is moving boldly toward the text, so, too, the text is calling to him. The attraction, and the action, is mutual and reciprocal.

Steiner's second step, penetration, is, like the first, perceived as an autonomous action on the part of the translator. The interpreter, self-confident and self-contained, enters the world of the source text as an intruder in order to take it and make it his own. The violence of the vocabulary, and its sexual connotations, are not accidental : it is a violent and appropriative movement Steiner is describing - a brutal rape rather than a scene of mutual seduction.

The second move of the translator is incursive and extractive. The relevant analysis is that of Heidegger when he focuses our attention on understanding as an act, on the access, inherently appropriative and therefore violent, or Erkenntnis to Dasein. Da-sein, the "thing there," "the thing that is because it is there," only comes into authentic being when it is comprehended, i.e. translated. The postulate that all cognition is aggressive, that every proposition is an inroad on the world, is, of course, Hegelian. It is Heidegger's contribution to have shown that understanding, recognition, interpretation are a compacted, unavoidable mode of attack. 5

The violence of the language used here rings true, but only partially so. Steiner's second step is, in fact, as he describes it, two steps - penetration and extraction. It is with the first of these that I would take issue - while it is true that the translator enters the text, and appears to do so as an autonomous individual, it is also true that this entry is in part achieved as a result of seduction on the part of the text, and through empathy on the part of the interpreter. It is a commonplace, but nonetheless true, that readers and playgoers have a natural impulse to identify with narrators or protagonists, and succeed in doing so, however hard novelists like Sarraute or Robbe-Grillet, or playwrights like Brecht, might try to prevent them. This is clearly true of literature, but I believe it is also true of semantic texts : though the reader is not identifying with a protagonist, he is adopting an attitude of sympathy with, or empathy for, the authorial voice.

Thus, this second step is more accurately described by dividing it into two parts : the first is a reciprocal movement, in which the interpreter both violates and identifies with the text: the second is the appropriative act by which he makes it his own. Even here, though, this is only a truly violent act if we see the individual who penetrates and appropriates as an autonomous and self-contained individual. If, however, we assume that the individual's consciousness is formed by the language he has encountered, then it is much less clear how violent and appropriative this language is: if his consciousness is made up of the language of others, then his appropriation of this new text is as much or more an alteration of his own consciousness as it is a transformation of the text. In sum, then, this second step may well be more accurately described as a merging of two consciousnesses, than as an appropriation of the one by the other. 
The difference between the terms "penetration" and "empathy" here is obvious; so, too, is the difference between the genders with which these words are associated. I would claim that, for some interpreters, penetration most aptly describes their relation with the text, and, for others, empathy is a more suitable expression. But the two are on a continuum, and elements of both actions are no doubt present for most interpreters.

Steiner acknowledges the merging of the writer's and the interpreter's consciousnesses in his third step, incorporation. The interpreter incorporates into his own being the work that he has appropriated, and in the process alters himself. Similarly, the culture which imports by means of translation texts taken from other cultures will be modified as a result. One analogy Steiner uses here is the partaking of the sacrament in religious ceremonies; in the Christian communion, for example, the communicant incorporates the bread and wine, which he sees as the body and blood of Christ, or symbols for them. By taking in the body and blood of Christ, the Christian believes he is sanctified, and thus transformed. Similarly, it has been a practice among many peoples to partake of the flesh of their conquered enemies, believing that this would enable them to share in the valor of these enemies. Thus, for many it has been a sign of admiration rather than one of disdain, to eat the flesh of another. In these two examples and many others, the point that is being made is that the incorporation of the alien element alters the state of the one who incorporates the other. This is important because it once more emphasizes the reciprocal nature of the hermeneutic motion. The individual who incorporates the alien text is altered by the experience: similarly, the culture which incorporates an alien text through translation is modified by the transaction.

The fourth move of the hermeneutic motion, restitution, is the means by which balance is restored. If translation, for Steiner, involves the translator's moving toward the text, appropriating it, and returning home with it, the act of translation clearly produces disequilibrium. The movement must be completed in some way which will restore the balance; there must be compensation in order to restore parity. The model Steiner uses here is Lévi-Strauss's Anthropologie structurale:

... which regards social structures as attempts at dynamic equilibrium achieved through an exchange of words, women, and material goods. All capture calls for subsequent compensation; utterance solicits response, exogamy and endogamy are mechanisms of equalizing transfer. Within the class of semantic exchanges, translation is again the most graphic, and most radically equitable. A translator is account-able to the diachronic and synchronic mobility and conservation of the energies of meaning. A translation is, more than figuratively, an act of double-entry; both formally and morally the book must balance ${ }^{6}$.

Thus, while the recipient culture is altered by the addition of the new text, so is the target culture, since the translated text is altered by the fact of its being translated.

Let us now turn to the moment of writing itself, and the further gaps this inevitably produces. Comparative linguistics has provided us with ample information about the differences among languages. If we believe, with Benjamin Whorf, that language is prior to thought, and that the structure of a language determines the possibility of thought within that language, it is clear that the writing of a thought first formulated in one language in a second will inevitably entail some slippage, however slight. Difference therefore becomes unavoidable, which perhaps explains to some degree why translation often proves more difficult than it appears it should, and why translators often feel that they have not been completely successful in their apparently fairly straightforward task. 
Steiner has shown in great detail the complexity of the act of interpretation which is so central to the translation process. Recent feminist thought leads us to reconsider his theory by giving greater emphasis, on the one hand, to the movement of the text toward the translator, and, on the other, to the movement of empathy which may link the translator and the text. Contemporary reading theory further encourages us to emphasize more than Steiner does the personal nature of the interpretive process, as affected by history, gender and personal idiosyncrasy. Finally, and perhaps most importantly, contemporary language and writing theory teach us that language is prior to and formative of thought, and that therefore the translation of pure thought from one language to another is an ideal which cannot be completely realized in practice.

Notes

1. See After Babel, London, Oxford University Press, 1985.

2. Steiner, p. 302.

3. Steiner, pp. $296-301$.

4. In Illuminations, trans. Harry Zohn, New York, Schocken Books, 1967, p. 82.

5. Steiner, p. 297.

6. Steiner, pp. $302-303$ 